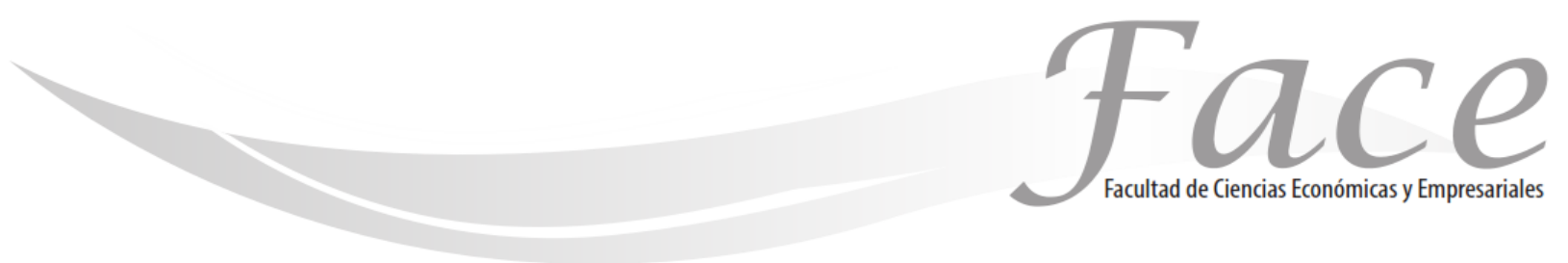

ISSN Impreso: 1794-9920

ISSN Electrónico: 2500-9338

Volumen $17-\mathrm{N}^{\circ} 2$

Año 2017

Págs. $26-42$

\title{
DINÁMICA DEL COMERCIO INTERNACIONAL DEL SECTOR AUTOPARTES DEL DEPARTAMENTO DE SANTANDER EN EL PERÍODO 2011-2015.*
}

\author{
Julio Ramírez Montañez ** \\ Enlace ORCID: http://orcid.org/ 0000-0002-6689-3345 \\ Gustavo González Sarmiento \\ Enlace ORCID: http://orcid.org/ 0000-0003-4138-8067 \\ Marco Vásquez Méndez \\ Enlace ORCID: http://orcid.org/ 0000-0001-8270-6792
}

Fecha de Recepción: enero 232017

Fecha de Aprobación: abril 72017

\section{Resumen:}

El patrón de producción de la cadena autopartes del departamento de Santander está enfocado en la fabricación de partes de ejes con diferencial, platos, prensas, discos y transmisiones cardánicas. En el año 2015, la cadena del sector autopartes del departamento de Santander aportó con un $2 \%$ a la producción total del país, generó el $4,23 \%$ de los empleos de este sector en el ámbito nacional. En cuanto al comercio internacional del sector autopartes, las importaciones del sector del departamento de Santander tuvieron su origen en Estados Unidos con un $28 \%$ de las importaciones, seguido de China con un $20 \%$ de las importaciones y Brasil con un 12\% de las importaciones del sector autopartes del departamento de Santander en el año 2015. Es de destacar que las exportaciones de autopartes del departamento de Santander han tenido una caída a partir del año 2012, teniendo una variación negativa en el período 2011-2015 de -68\% debido principalmente al traslado de la producción de la empresa DANA-Transejes fuera del departamento de Santander. Las exportaciones realizadas durante el 2015 están dirigidas hacia el mercado Ecuatoriano con un $50 \%$ de las exportaciones del sector autopartes de Santander y hacia los países miembros de la Alianza del Pacifico con el $\mathbf{2 8 . 7 \%}$ de las exportaciones. La empresa Transejes Transmisiones Homocinéticas de Colombia S.A es la empresa exportadora más representativa del sector autopartes del departamento con ventas por US $\$ 3.362 .255$.

Palabras Claves: Dinamismo del Comercio Internacional; Sector Autopartes; Departamento de Santander; Capitulo Arancelario 87

* Resultado de Proyecto de Investigación Interinstitucional "Dinámica Relativa del Comercio Intrarregional de los Países de la Alianza del Pacifico" Grupo GRICANI Facultad de Administración de Negocios Internacionales, Universidad Pontificia Bolivariana, Seccional Bucaramanga - Grupo por la Integración y la Globalización de los Negocios. Facultad de Negocios Universidad Santo Tomas Sede Bucaramanga 
Profesional en Relaciones Internacionales Magister en Relaciones Internacionales Docente Facultad de Administración de Negocios Internacionales Director del Grupo de Investigación GRICANI, Director de Investigación Escuela de Economía Administración y Negocios Universidad Pontificia Bolivariana Seccional Bucaramanga

Investigador del Grupo de Investigación por la Integración y la Globalización de los Negocios. Facultad de Negocios Universidad Santo Tomas Sede Bucaramanga. Facultad de Negocios Universidad Santo Tomas Sede Bucaramanga

Profesional en Administración de Negocios Internacionales. Universidad Pontificia Bolivariana Seccional Bucaramanga

\title{
DYNAMICS OF INTERNATIONAL TRADE IN THE AUTOPARTES SECTOR OF THE SANTANDER DEPARTMENT IN THE PERIOD 2011-2015
}

\begin{abstract}
The pattern of production of the chain auto parts of the department of Santander is focused on the manufacture of parts of axles with differential, dishes, presses, disks and spider transmissions. In the year 2015, the string in the auto parts sector of the department of Santander contributed with a 2 per cent to the total production of the country production, generated the 4.23 per cent of the jobs in this sector at the national level. In regard to international trade in the sector auto parts, imports in the sector of the department of Santander had their origin in the United States with a 28 per cent of imports, followed by China with a $20 \%$ of imports and Brazil with a 12 percent of imports of the auto parts sector of the department of Santander in the year 2015. It is noted that the exports of automotive parts of Santander department have had a fall from the year 2012, taking a negative variation in the period 2011-2015-68\% mainly due to the transfer of the production of the company DANA-Transaxles outside the department of Santander. Exports made during the 2015 are directed toward the Ecuadorian market with a $50 \%$ of the exports of the auto parts sector Santander and toward the member countries of the Alliance of the Pacific with the $28.7 \%$ of exports. The company Transaxles CV transmissions of Colombia S.A is the exporting company more representative of the auto parts sector of the department with sales of US\$3.362.255..
\end{abstract}

Keywords: Dynamic of International Trade; Auto parts Sector; Department of Santander; Chapter Quota 87

\section{DINÁMICA DO COMERCIO INTERNACIONAL DO SECTOR AUTOPARTES DEL DEPARTAMENTO DE SANTANDER NO PERÍODO 2011-2015. *}

\section{Resumo}

O padrão de produção do departamento de autopeças cadeia de Santander está focado na fabricação de peças de eixos com diferencial, placas, prensas, discos e transmissões cardânicos. Em 2015, a cadeia departamento de Santander indústria de autopeças fornecido com $2 \%$ da produção total do país, gerou $4,23 \%$ de postos de trabalho neste sector a nível nacional. Quanto ao comércio internacional na indústria de autopeças, as importações do Departamento de Indústria Santander originou nos Estados Unidos, com 28\% das importações, seguido pela China com $20 \%$ das importações e Brasil, com $12 \%$ das importações o departamento de Santander setor de autopeças em 2015. vale ressaltar que as exportações de autopeças departamento de Santander tiveram uma queda em relação ao ano de 2012, com uma variação negativa no período 2011-2015, devido, principalmente, $-68 \%$ a transferência da empresa de produção Dana-transaxles fora do departamento de Santander. Exportações em 2015 são dirigidas para o mercado equatoriano com 50\% das exportações do setor Santander autopeças e aos países membros da Aliança do Pacífico, com $28,7 \%$ das exportações. Os transaxles empresa Transmissions velocidade 
constante Colômbia S.à é o mais representativo da empresa exportadora setor de autopeças com o departamento de vendas de US \$ 3.362.255.

Palavras-chave Dinamismo do Comércio Internacional; Indústria partes; departamento de Santander; Capítulo 87 HS 


\section{INTRODUCCIÓN:}

Julio Ramírez Montañez-Gustavo González Sarmiento-Marco Vásquez Méndez

El presente artículo es resultado del proyecto de investigación Interinstitucional titulado "Dinámica Relativa del Comercio Intrarregional de los Sectores Metalmecánico y Autopartes de Colombia con los Países de la Alianza del Pacifico" llevado a cabo por investigadores de los grupos de investigación GRICANI de la Facultad de Administración de Negocios Internacionales de la Universidad Pontificia Bolivariana, Seccional Bucaramanga y el Grupo por la Integración y la Globalización de los Negocios de la Facultad de Negocios Internacionales de la Universidad Santo Tomas Sede Bucaramanga.

Los resultados de esta investigación son presentados en este artículo en dos secciones principales. En la primera de ellas, se presenta el análisis del sector autopartes del departamento de Santander usando las variables de participación del sector en la generación de empleo en el ámbito nacional y departamental, el valor agregado generado en el sector autopartes en el periodo 2010-2015, la producción bruta de la cadena metalmecánica en Colombia y en el departamento de Santander; así como la distribución regional de la producción, los destinos de las exportaciones y las perspectivas del sector metalmecánico en Colombia en los próximos años.

En la segunda sección se se presenta la Dinámica Comercial del Capítulo arancelario No 87 correspondiente a los productos del sector autopartes, tomando como referencia las exportaciones e importaciones de las partidas más dinámicas, principales productos exportados e importados y las principales empresas exportadoras e importadoras en el contexto global, nacional y Departame

\section{METODOLOGÍA:}

La metodología diseñada para el desarrollo de esta investigación fue de carácter descriptivo y documental y estuvo dividida en dos fases. En la primera fase se desarrolló mediante un análisis descriptivo del sector autopartes del Área Metropolitana de Bucaramanga en los últimos cinco años tomando como referencia las variables de empleo, valor agregado, producción bruta, distribución regional de la producción y principales productos exportados y destinos de las exportaciones de este sector en el Área Metropolitana de Bucaramanga utilizando las fuentes gubernamentales del Departamento Administrativo Nacional de Estadística (DANE) y del Programa de Transformación Productiva del Ministerio de Comercio Industria y Turismo de Colombia.

En la segunda fase, se desarrolla un análisis documental de la dinámica comercial del capítulo arancelario No 87 correspondiente a los productos del sector autopartes, tomando como referencia las variables de exportaciones, importaciones, principales productos exportados e importados, las principales empresas exportadoras e importadoras en el contexto global, nacional y Departamental utilizando las fuentes del Sistema Integrado de Estadísticas de Comercio Exterior SIEX y TradeMap.

\section{DISCUSION}

El propósito central de este artículo es presentar los aspectos más relevantes de la dinámica del comercio internacional del sector autopartes del departamento de Santander en los últimos cinco años. Para tal fin, se han tomado como variables de análisis la participación en la generación de empleo de la cadena autopartes, la producción industrial del sector y las exportaciones e importaciones y empresas importadoras e importadoras del capítulo arancelario No 87 al cual pertenecen las partidas arancelarias más dinámicas del sector autopartes de Colombia.

Esta sección centra su atención en presentar los aspectos más relevantes del sector autopartes en el contexto internacional, presentando inicialmente las partidas arancelarias más dinámicas en el sector autopartes, de igual forma se presenta la dinámica de la cadena comercial del sector autopartista en el contexto internacional, en Colombia y en el departamento de Santander, mediante un diagnóstico del comportamiento de las variables de empleo y producción del sector autopartes a nivel nacional y departamental.

La industria automotriz y de autopartes, así como el comercio de vehículos y autopartes, juegan un papel importante en la generación de empleo y valor agregado en la economía nacional. Su relevancia no radica exclusivamente en la producción, el comercio y el consumo final por parte de los hogares, sino que además incluye el rol que juega el sector automotor en el quehacer de los demás sectores de la economía. (Reina \& Oviedo, 2014).

3.1 Dinámica Comercial del Sector Autopartes en el Contexto Internacional (Capitulo Arancelario No 87)

Actualmente el sector de autopartes hace parte de la cadena de valor automotriz y está compuesto por actividades de suministro para ensamble de vehículos y el mercado de reposición (chasis, interiores, exteriores, eléctricos y electrónicos). (Escandón, \& Hurtado, 2013).

En Colombia, se fabrican diversos tipos de autopartes, entre las que se encuentran: sistemas de suspensión, sistemas de dirección, sistemas de escape, sistemas de transmisión, sistemas de refrigeración, material de fricción, partes eléctricas como baterías y cableados, productos 
químicos, rines, llantas, filtros para aire, lubricantes y combustibles, tapicerías en tela y cuero, vidrios templados, laminados y para blindaje, bastidores de chasis, aires acondicionados, partes de caucho y metal y accesorios, entre otros. (Escandón, \& Hurtado, 2013)

La industria automotriz nace en Colombia con los talleres de mantenimiento, incursionando luego en la reposición de partes y piezas, hasta llegar al proceso de ensamblaje. En ese sentido, actualmente en Colombia se identifican varios nichos de negocio dentro de la cadena productiva: ensambladoras de automóviles, ensambladoras de motos, fabricantes de autopartes, concesionarios de automotores, distribuidoras de repuestos, y servicios de postventa.

A pesar de que el país no es uno de los principales participantes internacionales en el sector industrial automotriz, este sector juega un papel fundamental en el desarrollo de la economía nacional, gracias a sus aportes de recaudación fiscal, generación de valor agregado y creación de fuentes de trabajo. Las empresas proveedoras de estos equipos y repuestos tienen certificados sus procesos de gestión con normas internacionales, además de las normas privadas de las grandes casas matrices mundiales de vehículos para las cuales la industria autopartista es proveedor en Colombia, Venezuela y Ecuador, entre otras. El origen de las inversiones en esta actividad proviene principalmente de la industria nacional, la cual atrae inversiones de Estados Unidos, Japón, Francia, México, Brasil, Venezuela, lo que además incluye asistencia técnica de productores mundiales de partes eléctricas, llantas, vidrio, partes de transmisión. (Acevedo, M. \& Santana, G., 2014).

A continuación se presentan los capítulos arancelarios correspondientes al capítulo 87 , el cual clasifica los principales productos del sector autopartes.

\subsubsection{Principales Partidas Arancelarias Capitulo 87}

La dinámica del capítulo arancelario No 87 en el contexto internacional comprende las partidas arancelarias que van desde la 87.01 hasta las partidas 87.16 , las cuales son presentadas en el cuadro No 1

\section{Cuadro No 1 Principales Partidas Arancelarias Capitulo 87}

\begin{tabular}{|c|c|}
\hline Partida & Descripción \\
\hline 87.01 & Tractores (Excepto Las Carretillas Tractor De La Partida 8709) \\
\hline 87.02 & $\begin{array}{c}\text { Vehículos Automóviles Para Transporte De Diez O Más } \\
\text { Personas, Incluido El Conductor }\end{array}$ \\
\hline 87.03 & $\begin{array}{c}\text { Automóviles De Turismo Y Demás Vehículos Automóviles } \\
\text { Concebidos Principalmente Para Transporte De Personas } \\
\text { (Excepto Los De La Partida 8702), Incluidos Los Del Tipo } \\
\text { Familiar (Break O Station Wagon) Y Los De Carreras }\end{array}$ \\
\hline 87.04 & Vehículos Automóviles Para Transporte De Mercancías \\
\hline
\end{tabular}

\begin{tabular}{|c|c|}
\hline 87.05 & $\begin{array}{c}\text { Vehículos Automóviles Para Usos Especiales (Excepto Los } \\
\text { Concebidos Principalmente Para Transporte De Personas O } \\
\text { Mercancías) [Por Ejemplo: Coches Para Reparaciones (Auxilio } \\
\text { Mecánico), Camiones Grúa, Camiones De Bomberos, } \\
\text { Camiones Hormigonera, Coches Barre }\end{array}$ \\
\hline 87.06 & $\begin{array}{c}\text { Chasis De Vehículos Automóviles De Las Partidas } 8701 \text { A } \\
\text { 8705, Equipados Con Su Motor }\end{array}$ \\
\hline 87.07 & $\begin{array}{c}\text { Carrocerías De Vehículos Automóviles De Las Partidas } 8701 \text { A } \\
\text { 8705, Incluidas Las Cabinas }\end{array}$ \\
\hline 87.08 & $\begin{array}{c}\text { Partes Y Accesorios De Vehículos Automóviles De Las } \\
\text { Partidas } 8701 \text { A } 8705\end{array}$ \\
\hline 87.09 & $\begin{array}{l}\text { " Carretillas Automóvil Sin Dispositivo De Elevación Del Tipo } \\
\text { De Las Utilizadas En Fábricas, Almacenes, Puertos O } \\
\text { Aeropuertos, Para Transporte De Mercancias A Corta } \\
\text { Distancia; Carretillas Tractor Del Tipo De Las Utilizadas En Las } \\
\text { Estaciones Ferroviarias; }\end{array}$ \\
\hline 87.10 & $\begin{array}{l}\text { "Tanques Y Demás Vehículos Automóviles Blindados De } \\
\text { Combate, Incluso Con Su Armamento; Sus Partes" }\end{array}$ \\
\hline 87.11 & $\begin{array}{c}\text { " Motocicletas, Incluidos Los Ciclomotores, Y Velocípedos } \\
\text { Equipados Con Motor Auxiliar, Con Sidecar O Sin Él; } \\
\text { Sidecares" }\end{array}$ \\
\hline 87.12 & $\begin{array}{c}\text { Bicicletas Y Demás Velocípedos, Incluidos Los Triciclos De } \\
\text { Reparto, Sin Motor }\end{array}$ \\
\hline 87.13 & $\begin{array}{l}\text { Sillones De Ruedas Y Demás Vehículos Para Inválidos, } \\
\text { Incluso Con Motor U Otro Mecanismo De Propulsión }\end{array}$ \\
\hline 87.14 & $\begin{array}{l}\text { Partes Y Accesorios De Vehículos De Las Partidas } 8711 \text { A } \\
\qquad 8713\end{array}$ \\
\hline 87.15 & $\begin{array}{c}\text { Coches, Sillas Y Vehículos Similares Para Transporte De } \\
\text { Niños, Y Sus Partes }\end{array}$ \\
\hline 87.16 & $\begin{array}{c}\text { "Remolques Y Semirremolques Para Cualquier Vehículo; Los } \\
\text { Demás Vehículos No Automóviles; Sus Partes" }\end{array}$ \\
\hline
\end{tabular}

Como se puede apreciar en el cuadro anterior las partidas arancelarias del capítulo 87 clasifica a productos del sector autopartes, los cuales son tan disimiles que van desde tractores, tanques y vehículos blindados hasta motocicletas, bicicletas y sillas de ruedas, pasando por vehículos, chasis y partes y accesorios de vehículos.

En el cuadro No 2 se presenta la dinámica de exportaciones e importaciones a nivel mundial en el periodo 2011-2015. Allí se puede apreciar un dinamismo constante en el comercio exterior del capítulo arancelario 87, pasando de exportar US\$1.273.093.076 en el año 2011 a exportar US\$ 1.311.247.408 en el año 2015, presentándose un incremento mundial de las exportaciones del sector autopartes en casi un $10 \%$ en el periodo 2011 2015.

De igual forma, se puede apreciar que las importaciones incrementaron en un $10 \%$ al pasar de transar US\$ 1.261.825.832 en el año 2011 a importar US\$1.324.167.954 en el año 2015, lo cual ilustra la gran dinámica comercial de los productos del sector autopartes en mercados internacionales.

Cuadro No 2 Importaciones y exportaciones mundiales: CAPÍTULO 87 (USD Miles) 
Julio Ramírez Montañez-Gustavo González Sarmiento-Marco Vásquez Méndez

\begin{tabular}{|c|c|c|c|c|c|}
\hline $\begin{array}{c}\text { Añol } \\
\text { Transac } \\
\text { ción }\end{array}$ & $\mathbf{2 0 1 5}$ & $\mathbf{2 0 1 4}$ & $\mathbf{2 0 1 3}$ & $\mathbf{2 0 1 2}$ & $\mathbf{2 0 1 1}$ \\
\hline $\begin{array}{c}\text { Exportac } \\
\text { iones }\end{array}$ & 1.311 .24 & 1.392 .79 & 1.352 .03 & 1.305 .84 & 1.273 .09 \\
\hline $\begin{array}{c}\text { Importac } \\
\text { iones }\end{array}$ & 1.324 .16 & 2.719 & 7.209 & 0.642 & 3.076 \\
\hline & 7.954 & 0.895 & 6.410 & 2.450 & 5.832 \\
\hline
\end{tabular}

Fuente: Trademap (2016)

\subsubsection{Principales Países Exportadores Capitulo 87}

El cuadro No 3 presenta los principales países exportadores de productos correspondientes al capítulo 87. Alemania es el país líder en las exportaciones del capítulo 87 a nivel mundial aportando casi el $20 \%$ de las exportaciones mundiales con montos superiores a los US $\$ 240.000$ en el periodo 2011- 2015. El segundo país exportador del capítulo 87 es Japón aportando el 18\% de las exportaciones mundiales del sector autopartes en mercados internacionales en el año 2015. Estados Unidos es el tercer competidor en las exportaciones del capítulo 87 con ventas internacionales de US\$127.113.562 en el año 2015 representando el $9 \%$ de las exportaciones mundiales en este año. El Primer país Latinoamericano del ranking de exportadores del capítulo 87 es México con ventas por US\$ 90.363 .239 en el año 2015 representando el $6.8 \%$ de las exportaciones mundiales.

De igual forma es importante resaltar la importante evolución de las exportaciones del capítulo 87 de China en donde paso de exportar US\$ 49.539.445 en el año 2011 a exportar US\$ 62.651 .637 teniendo un incremento porcentual $79 \%$ en el periodo $2011-2015$

\section{Cuadro No 3 Principales países Exportadores Capitulo} 87

\begin{tabular}{|c|c|c|c|c|c|c|}
\hline \multicolumn{7}{|c|}{$\begin{array}{l}\text { PRINCIPALES PAÍSES EXPORTADORES - CAPITULO } 87 \text { (USD\$ } \\
\text { MILES) }\end{array}$} \\
\hline $\begin{array}{l}\text { Pue } \\
\text { sto }\end{array}$ & País & 2011 & 2012 & 2013 & 2014 & 2015 \\
\hline \multicolumn{2}{|c|}{ MUNDO } & $\begin{array}{l}1.273 .0 \\
93.076\end{array}$ & $\begin{array}{l}1.305 .8 \\
40.642\end{array}$ & $\begin{array}{l}1.352 .0 \\
37.209\end{array}$ & $\begin{array}{l}1.392 .7 \\
92.719\end{array}$ & \\
\hline 1 & $\begin{array}{c}\text { Alem } \\
\text { ania }\end{array}$ & $\begin{array}{c}247.242 \\
.094\end{array}$ & $\begin{array}{c}235.525 \\
.858\end{array}$ & $\begin{array}{c}243.244 \\
.304\end{array}$ & $\begin{array}{c}259.423 \\
.134\end{array}$ & $\begin{array}{c}241.444 \\
.373\end{array}$ \\
\hline 2 & $\begin{array}{c}\text { Japó } \\
\mathrm{n}\end{array}$ & $\begin{array}{c}148.057 \\
.286\end{array}$ & $\begin{array}{c}162.829 \\
.579\end{array}$ & $\begin{array}{c}148.549 \\
.339\end{array}$ & $\begin{array}{c}142.513 \\
.899\end{array}$ & $\begin{array}{c}134.047 \\
.862\end{array}$ \\
\hline
\end{tabular}

\begin{tabular}{|c|c|c|c|c|c|c|}
\hline 3 & $\begin{array}{c}\text { Estad } \\
\text { os } \\
\text { Unid } \\
\text { os }\end{array}$ & $\begin{array}{c}120.011 \\
.781\end{array}$ & $\begin{array}{c}133.078 \\
.053\end{array}$ & $\begin{array}{c}134.084 \\
.552\end{array}$ & $\begin{array}{c}135.972 \\
.388\end{array}$ & $\begin{array}{c}127.113 \\
.562\end{array}$ \\
\hline 4 & $\begin{array}{c}\text { Méxi } \\
\text { co }\end{array}$ & $\begin{array}{c}62.900 . \\
758\end{array}$ & $\begin{array}{c}70.272 \\
844\end{array}$ & $\begin{array}{c}77.192 . \\
992\end{array}$ & $\begin{array}{c}85.955 \\
743\end{array}$ & $\begin{array}{c}90.363 \\
239\end{array}$ \\
\hline 5 & $\begin{array}{c}\text { Repú } \\
\text { blica } \\
\text { de } \\
\text { Core } \\
\text { a }\end{array}$ & $\begin{array}{c}67.096 . \\
998\end{array}$ & $\begin{array}{c}70.074 \\
094\end{array}$ & $\begin{array}{c}72.771 . \\
813\end{array}$ & $\begin{array}{c}73.343 \\
530\end{array}$ & $\begin{array}{c}69.058 \\
752\end{array}$ \\
\hline 6 & $\begin{array}{c}\text { Chin } \\
\text { a }\end{array}$ & $\begin{array}{c}49.539 \\
445\end{array}$ & $\begin{array}{c}55.117 \\
129\end{array}$ & $\begin{array}{c}58.549 . \\
754\end{array}$ & $\begin{array}{c}64.195 \\
842\end{array}$ & $\begin{array}{c}62.651 \\
637\end{array}$ \\
\hline 7 & $\begin{array}{c}\text { Cana } \\
\text { dá }\end{array}$ & $\begin{array}{c}52.864 . \\
601\end{array}$ & $\begin{array}{c}61.297 \\
640\end{array}$ & $\begin{array}{c}59.268 \\
456\end{array}$ & $\begin{array}{c}59.707 \\
397\end{array}$ & $\begin{array}{c}60.108 \\
862\end{array}$ \\
\hline 8 & $\begin{array}{c}\text { Rein } \\
0 \\
\text { Unid } \\
0\end{array}$ & $\begin{array}{c}46.022 \\
808\end{array}$ & $\begin{array}{c}47.533 \\
882\end{array}$ & $\begin{array}{c}50.994 . \\
806\end{array}$ & $\begin{array}{c}54.409 . \\
455\end{array}$ & $\begin{array}{c}50.720 \\
272\end{array}$ \\
\hline 9 & $\begin{array}{c}\text { Espa } \\
\text { ña }\end{array}$ & $\begin{array}{c}50.396 . \\
697\end{array}$ & $\begin{array}{c}42.223 . \\
161\end{array}$ & $\begin{array}{c}48.438 \\
827\end{array}$ & $\begin{array}{c}51.639 . \\
220\end{array}$ & $\begin{array}{c}49.701 . \\
780\end{array}$ \\
\hline 10 & $\begin{array}{c}\text { Franc } \\
\text { ia }\end{array}$ & $\begin{array}{c}53.925 . \\
753\end{array}$ & $\begin{array}{c}47.435 . \\
092\end{array}$ & $\begin{array}{c}46.542 . \\
937\end{array}$ & $\begin{array}{c}47.618 \\
292\end{array}$ & $\begin{array}{c}45.021 \\
215\end{array}$ \\
\hline
\end{tabular}

Fuente: Trademap (2016)

\subsubsection{Principales Países Exportadores Capitulo 87}

El principal país importador de productos del sector autopartes es Estados Unidos al importar US\$ 283.754.046 en el año 2015 aportando el 21\% de las importaciones mundiales de esta partida arancelaria. Alemania es el segundo país importador del capítulo 87 al importar US\$ 100.309.576 correspondiente al $7 \%$ de las importaciones mundiales. Se ubica en el tercer lugar de las importaciones del capítulo 87 el Reino Unido con importaciones por US\$ 78.091.339 en el año 2015. México se ubica en la novena posición con importaciones por un monto de US\$ 37.265.337 en el año 2015 aportando el 2.8\% de las importaciones mundiales del capítulo 87.

\section{Cuadro No 4 Principales países Importadores Capitulo 87}

\begin{tabular}{|c|c|c|c|c|c|c|}
\hline \multicolumn{7}{|c|}{ MILES) } \\
\hline Pue & País & 2011 & 2012 & 2013 & 2014 & 2015 \\
\hline sto & & & & & & \\
\hline \multirow{2}{*}{\multicolumn{2}{|c|}{ MUNDO }} & 1.261 .8 & 1.302 .7 & 1.347 .4 & 1.398 .7 & 1.324 .1 \\
\hline & & 25.832 & 42.450 & 96.410 & 10.895 & 67.954 \\
\hline \multirow[t]{3}{*}{1} & Esta & 206.182 & 244.174 & 253.081 & 265.323 & 283.754 \\
\hline & dos & .707 & .855 & .966 & .956 & .046 \\
\hline & Unid & & & & & \\
\hline
\end{tabular}




\begin{tabular}{|c|c|c|c|c|c|c|}
\hline & os & & & & & \\
\hline 2 & $\begin{array}{l}\text { Alem } \\
\text { ania }\end{array}$ & $\begin{array}{c}98.303 \\
563\end{array}$ & $\begin{array}{c}93.134 . \\
274\end{array}$ & $\begin{array}{c}96.717 \\
933\end{array}$ & $\begin{array}{c}104.945 \\
.392\end{array}$ & $\begin{array}{c}100.309 \\
.576\end{array}$ \\
\hline 3 & $\begin{array}{c}\text { Rein } \\
0 \\
\text { Unid } \\
0\end{array}$ & $\begin{array}{c}69.497 . \\
459\end{array}$ & $\begin{array}{c}59.815 \\
133\end{array}$ & $\begin{array}{c}66.131 . \\
322\end{array}$ & $\begin{array}{c}76.382 . \\
456\end{array}$ & $\begin{array}{c}78.091 . \\
339\end{array}$ \\
\hline 4 & $\begin{array}{c}\text { Chin } \\
\text { a }\end{array}$ & $\begin{array}{c}65.438 \\
574\end{array}$ & $\begin{array}{c}70.596 \\
739\end{array}$ & $\begin{array}{c}74.147 . \\
799\end{array}$ & $\begin{array}{c}89.506 . \\
422\end{array}$ & $\begin{array}{c}69.607 . \\
641\end{array}$ \\
\hline 5 & $\begin{array}{c}\text { Cana } \\
\text { dá }\end{array}$ & $\begin{array}{c}64.253 . \\
063\end{array}$ & $\begin{array}{c}70.748 \\
497\end{array}$ & $\begin{array}{c}71.673 . \\
896\end{array}$ & $\begin{array}{c}70.522 \\
278\end{array}$ & $\begin{array}{c}66.818 \\
514\end{array}$ \\
\hline 6 & $\begin{array}{c}\text { Fran } \\
\text { cia }\end{array}$ & $\begin{array}{c}65.653 \\
779\end{array}$ & $\begin{array}{c}55.634 \\
121\end{array}$ & $\begin{array}{c}57.237 . \\
079\end{array}$ & $\begin{array}{c}58.261 . \\
276\end{array}$ & $\begin{array}{c}57.888 . \\
335\end{array}$ \\
\hline 7 & $\begin{array}{c}\text { Bélgi } \\
\text { ca }\end{array}$ & $\begin{array}{c}45.070 \\
056\end{array}$ & $\begin{array}{c}42.352 \\
185\end{array}$ & $\begin{array}{c}48.793 . \\
036\end{array}$ & $\begin{array}{c}44.264 . \\
628\end{array}$ & $\begin{array}{c}42.506 . \\
978\end{array}$ \\
\hline 8 & $\begin{array}{c}\text { Espa } \\
\text { ña }\end{array}$ & $\begin{array}{c}35.992 . \\
168\end{array}$ & $\begin{array}{c}28.248 \\
480\end{array}$ & $\begin{array}{c}32.376 \\
149\end{array}$ & $\begin{array}{c}39.479 \\
378\end{array}$ & $\begin{array}{c}38.809 \\
695\end{array}$ \\
\hline 9 & $\begin{array}{c}\text { Méxi } \\
\text { co }\end{array}$ & $\begin{array}{c}28.571 \\
048\end{array}$ & $\begin{array}{c}32.426 . \\
951\end{array}$ & $\begin{array}{c}33.393 . \\
764\end{array}$ & $\begin{array}{c}35.735 \\
186\end{array}$ & $\begin{array}{c}37.265 . \\
337\end{array}$ \\
\hline 10 & Italia & $\begin{array}{c}44.759 . \\
052\end{array}$ & $\begin{array}{c}32.041 \\
128\end{array}$ & $\begin{array}{c}32.752 \\
649\end{array}$ & $\begin{array}{c}36.164 \\
801\end{array}$ & $\begin{array}{c}36.339 . \\
905\end{array}$ \\
\hline
\end{tabular}

Fuente: Trademap (2016)

3.2 Sector Autopartes de Colombia

En la presente sección se ofrece un análisis del sector autopartes del departamento de Santander usando las variables de participación del sector en la generación de empleo en el ámbito nacional y departamental, el valor agregado generado en el sector autopartes en el periodo 2010-2015, la producción bruta de la cadena metalmecánica en Colombia y en el departamento de Santander; así como la distribución regional de la producción.

El sector de autopartes en Colombia corresponde al ensamble de vehículos. En este sentido, la producción nacional se divide en: Fabricación de vehículos automotores y sus motores, Fabricación de carrocerías par vehículos automotores, Fabricación de partes, piezas y accesorios (autopartes) para vehículos automotores y sus motores. (Hormaza, P., \& Tovar, S., 2012).

3.2.1 Empleo del Sector Autopartes de Colombia

La primer variable de análisis es el empleo del sector autopartes de Colombia. Para realizar el análisis del empleo en la cadena productiva del sector autopartes de Colombia se han usado las variables de distribución regional del empleo en los principales departamentos colombianos productores del sector autopartes, la evolución del empleo en Colombia y el departamento de
Santander y el comportamiento del empleo en las principales Áreas Metropolitanas de Colombia.

En el cuadro No 5 se puede apreciar el comportamiento del empleo de la cadena autopartes de Colombia y su distribución por departamento. En este cuadro se muestra como el sector autopartista generó un total de 26.880 plazas de trabajo a nivel nacional. La ciudad de Bogotá es líder a nivel nacional en la producción de empleos del sector generando 10 mil empleos equivalentes al $39.81 \%$ del total de empleos de la cadena autopartista. El segundo departamento generador de empleo de la cadena autopartes en el Valle del Cauca con un $15.66 \%$ de la cadena del sector autopartes seguido por Risaralda con 3 mil empleos un $9.78 \%$ de participación del empleo a nivel nacional.

El departamento de Santander se ve rezagado en el séptimo lugar de la clasificación de departamentos generadores de empleo con una participación reducida de tan solo el 4,23\% de participación del empleo de este sector equivalente a 1.137 empleos en el año 2015.

Ante esta realidad, se puede resaltar que Bogotá es el gran generador de empleo de la cadena autopartes con el $39,81 \%$ de los empleos, otro punto a resaltar es que el empleo en sector autopartes se genera en su gran mayoría en los departamentos de la Región Andina de Colombia, con el $78 \%$ de los puestos de empleo de la cadena autopartes de Colombia.

\section{Cuadro No 5 Empleo Por Departamento Sector Autopartes Año 2015}

\begin{tabular}{|c|c|c|}
\hline Departamento & $\begin{array}{c}\text { Número de } \\
\text { Empleos }\end{array}$ & \% de empleados \\
\hline Bogotá & 10.701 & $39,81 \%$ \\
\hline Valle & 4.209 & $15,66 \%$ \\
\hline Risaralda & 2.629 & $9,78 \%$ \\
\hline Cundinamarca & 3.059 & $11,38 \%$ \\
\hline Antioquia & 2.465 & $9,17 \%$ \\
\hline Boyacá & 1.169 & $4,35 \%$ \\
\hline Santander & 1137 & $4,23 \%$ \\
\hline Caldas & 820 & $2,22 \%$ \\
\hline Atlántico & 1000 & $1,90 \%$ \\
\hline
\end{tabular}


Julio Ramírez Montañez-Gustavo González Sarmiento-Marco Vásquez Méndez

\begin{tabular}{|c|c|c|}
\hline Córdoba & 40 & $0,81 \%$ \\
\hline Norte de Santander & 20 & $0,71 \%$ \\
\hline Total & 26.880 & $100 \%$ \\
\hline
\end{tabular}

Fuente: (DANE, 2016). Elaboración Propia

Por su parte, la gráfica No 1 muestra como el sector autopartista aportó en el periodo 2010-2014 tuvo un crecimiento promedio del $28 \%$ en el periodo comprendido entre los años 2010-2014. En el caso de la dinámica del empleo del sector autopartes del departamento de Santander 2014 se contrajo pasando de crecer el $2 \%$ en el año 2010 a tan solo el $1.5 \%$ en el año 2014, esto originado principalmente debido al traslado de la producción de la empresa DANA-Transejes fuera del departamento de Santander, el cual fue un golpe muy fuerte al empleo del sector autopartista de Santander.

Fuente: (DANE, 2016). Elaboración Propia

Grafico No 1 Evolución del Empleo en el Sector

Autopartes.

\subsubsection{Comportamiento del Empleo de la Cadena del}

Sector Autopartes según Áreas Metropolitanas de

\section{Colombia}

El indicador de empleo de la cadena del sector autopartes en las principales Áreas Metropolitanas de Colombia que se presenta en el cuadro No 6 tuvo un desempeño positivo en la totalidad de Áreas Metropolitanas del país. Bogotá es el Área Metropolitana con mayor número de puestos de trabajo en el país al generar el $51.6 \%$ de los empleos de la cadena autopartista en el año 2015. El Área Metropolitana con mejor desempeño fue el Área Metropolitana de Cali realizando un aporte significativo a la generación de empleo en la cadena del sector autopartes con un $15.6 \%$ del total de puestos de trabajo del sector en Colombia, seguido por Medellín con un $11.9 \%$ y en cuarto lugar Pereira con un $8.9 \%$. Se resalta de igual forma, la importante participación del Área Metropolitana de Bucaramanga compuesta por los municipios de Floridablanca, Piedecuesta, Girón y Bucaramanga con un $4.2 \%$ de la participación de empleo del total de la Áreas Metropolitanas del país con 1.008 empleos. (DANE, 2016).
Cuadro No 6 Empleo Por Área Metropolitana del Sector

\section{Autopartes de Colombia}

\begin{tabular}{|c|c|c|}
\hline Ciudad & Participación\% & Participación \\
\hline Bogotá & $51,60 \%$ & 12.384 \\
\hline Cali & $15,60 \%$ & 3.744 \\
\hline Medellín & $11,90 \%$ & 2.856 \\
\hline Pereira & $8,90 \%$ & 2.136 \\
\hline Bucaramanga & $4,20 \%$ & 1.008 \\
\hline Barranquilla & $2,50 \%$ & 600 \\
\hline Manizales & $2,40 \%$ & 576 \\
\hline Cúcuta & $0,90 \%$ & 216 \\
\hline Ibagué & $0,80 \%$ & 192 \\
\hline Villavicencio & $0,70 \%$ & 168 \\
\hline Pasto & $0,30 \%$ & 72 \\
\hline Cartagena & $0,10 \%$ & 24 \\
\hline Montería & $0,10 \%$ & 24 \\
\hline Total & $100,00 \%$ & 24.000 \\
\hline
\end{tabular}

fuente: (DANE, 2016). Elaboración Propia

Es de destacar en el cuadro anterior que el $80.7 \%$ del empleo corresponde a Áreas Metropolitanas de la Región

Andina de Colombia.

\subsubsection{Distribución Regional de la Producción}

La distribución regional de la producción que se presenta a continuación se divide en dos fases. En la primera de ellas se presenta la producción bruta del sector autopartes de Colombia por Departamento y en la segunda parte se presenta la distribución de la producción y Distribución Regional de las Empresas del Sector Metalmecánico en Colombia y el Departamento de Santander. 


\subsubsection{Producción Bruta del Sector Autopartes}

El Valor Bruto de la Producción es la suma total de los valores de los bienes y servicios producidos por una sociedad, independientemente de que se trate de bienes intermedios que se utilizan en el proceso productivo o de artículos que se destinan al consumidor final. Por lo tanto, incluye el Valor de todos los productos sin considerar si son de Consumo intermedio o de consumo final. Para el caso del sector autopartes de Colombia en el año 2015 se puede apreciar que la Producción Bruta de Colombia fue de $\$ 6.754 .802$ millones. El Departamento líder de este sector es Bogotá con \$ 3.055.194 millones seguida por el Departamento de Antioquia con \$2.116.941 millones y por el Valle del Cauca con \$ 502.192 millones La Producción Bruta del departamento de Santander se limitó a \$105. 252 millones en el año 2015.

\section{Cuadro No 7 Producción Bruta por Departamento (Miles de Millones \$) Año 2015}

\begin{tabular}{|c|c|}
\hline DEPARTAMENTO & Producción Bruta \\
\hline Antioquia & 2.116 .941 \\
\hline Atlántico & 5.396 \\
\hline Bogotá & 3.055 .194 \\
\hline Boyacá & 48.179 \\
\hline Cundinamarca & 822.839 \\
\hline Risaralda & 98.809 \\
\hline Santander & 105.252 \\
\hline Valle del Cauca & 502.192 \\
\hline Total Nacional & 6.754 .802 \\
\hline
\end{tabular}

Fuente: (DANE, 2016). Elaboración Propia

\subsubsection{Distribución de la Producción}

La distribución de la producción del sector autopartes de Colombia está liderada por Bogotá con un $45 \%$ de la Producción total de este sector. El segundo departamento de mayor producción de la cadena de autopartes es Antioquía con el $31 \%$ de la producción, seguido por el departamento del Valle del Cauca con el $7 \%$ La producción del sector autopartes del departamento de Santander se reduce a tan solo el $2 \%$ de la producción de autopartes del país.

\author{
Cuadro No 8 Distribución de la Producción por \\ Departamento
}

\begin{tabular}{|c|c|}
\hline Departamento & Participación \% \\
\hline Bogotá & $45 \%$ \\
\hline Antioquia & $31 \%$ \\
\hline Cundinamarca & $12 \%$ \\
\hline Valle Del Cauca & $7 \%$ \\
\hline Santander & $2 \%$ \\
\hline Risaralda & $2 \%$ \\
\hline Otros & $1 \%$ \\
\hline Fuente: (DANE, 2016). Elaboración Propia & \\
\hline
\end{tabular}

\subsubsection{Distribución Regional de las Empresas del Sector Metalmecánico en Colombia y el}

Departamento de Santander

En el año 2015 en todo el territorio nacional hay registradas 268 empresas del sector autopartes. Las empresas de autopartes del sector están concentradas principalmente en Bogotá con 139 establecimientos tal y como lo señala el cuadro No 5 , el segundo departamento con más empresas del sector autopartes es Antioquia con 48 empresas seguido por el departamento de Cundinamarca con 33, 10 cual indica que la región Andina del país tiene 172 establecimientos productores de autopartes. En el caso de Santander, este departamento cuenta con 14 establecimientos del sector, ubicándose en la quinta posición del total de empresas de autopartes en el país.

Es importante precisar cómo en Bogotá existe una dinámica particular que muestra que hay una aparente satisfacción por parte de las empresas de este sector en cuanto a sus ventas y crecimiento se refiere. Teniendo en cuenta el término de internacionalización, se dice que hace referencia a todo conjunto que facilita el establecimiento de vínculos más o menos estables entre la empresa y los mercados internacionales a lo largo de un proceso de creciente implicación y proyección internacional. (Silva, 2013). 


\section{Cuadro No 9 Número de empresas por Departamento.}

\begin{tabular}{|c|c|}
\hline DEPARTAMENTO & $\mathbf{N}^{\circ}$ Establecimientos \\
\hline Bogotá & 139 \\
\hline Antioquia & 48 \\
\hline Cundinamarca & 33 \\
\hline Valle del Cauca & 24 \\
\hline Santander & 14 \\
\hline Atlántico & 3 \\
\hline Boyacá & 4 \\
\hline Risaralda & 3 \\
\hline Total Nacional & $\mathbf{2 6 8}$ \\
\hline
\end{tabular}

Fuente: (DANE, 2016). Elaboración Propia

Según la Cámara de Comercio de Bucaramanga (2015) estas empresas son: Transejes Transmisiones Homocinéticas de Colombia S.A; Industria De Ejes y Transmisiones S.A; Sol Parts Distribuidora Limitada; Importadora de Repuestos de Colombia S.A.S; Imrepcol Solutra de Colombia Ltda.; Madasa S.A.S; Trienergy S.A; C.I. del Tropiko Limitada; industrias Bicicletas Milán S.A; Safrenos Rangel S.A.S; Len Importaciones Ltda.; DCN S.A.S; Autopartes Castelmotors y Redemotos S.A.S

\subsubsection{Empresas Grandes y Medianas del Sector Autopartes en Colombia}

El cuadro No 10 señala la participación de las empresas grandes y medianas del sector autopartes de Colombia. Se puede apreciar que el $53.72 \%$ de las grandes y medianas empresas del sector autopartes de Colombia se ubican en la ciudad de Bogotá. En segundo lugar se encuentra el departamento de Cundinamarca con el $17.36 \%$ de las grandes y medianas empresas, seguido por el Valle del Cauca con $10,74 \%$ de este tipo de empresas. El departamento de Santander se encuentra en el quinto lugar con el $4.13 \%$ de las empresas.

\section{Cuadro No 10 Empresas Mediana y Grandes del Sector Autopartes de Colombia}

\begin{tabular}{|c|c|}
\hline Departamento & Concentración del sector\% \\
\hline Bogotá & $53,72 \%$ \\
\hline Cundinamarca & $17,36 \%$ \\
\hline Valle del Cauca & $10,74 \%$ \\
\hline Antioquia & $9,92 \%$ \\
\hline Santander & $4,13 \%$ \\
\hline Risaralda & $1,65 \%$ \\
\hline Huila & $0,83 \%$ \\
\hline Atlántico & $0,83 \%$ \\
\hline Cauca & $0,83 \%$ \\
\hline
\end{tabular}

Fuente: (DANE, 2016). Elaboración Propia

\subsubsection{Empresas Micro y Pequeñas del Sector Autopartes en Colombia}

De igual forma las Pequeñas y Micro empresas del sector autopartes se encuentran ubicadas en su gran mayoría, tal y como sucede con las grandes empresas en la ciudad de Bogotá con un $55.5 \%$ del total de micro y pequeñas empresas del sector autopartes. En el departamento de Antioquia se encuentran ubicadas el $12 \%$ de los micros y pequeñas empresas de la cadena de autopartes. En el departamento de Santander se encuentran ubicadas el $4 \%$ del total de este tipo de empresas.

\section{Cuadro No 11 Empresas Micro y Pequeñas}

\begin{tabular}{|c|c|}
\hline Departamento & Concentración del sector\% \\
\hline Bogotá & $55,5 \%$ \\
\hline Antioquia & $12 \%$ \\
\hline Valle del Cauca & $7,8 \%$ \\
\hline Atlántico & $7 \%$ \\
\hline
\end{tabular}




\begin{tabular}{|c|c|}
\hline Santander & $4 \%$ \\
\hline Boyacá & $2,3 \%$ \\
\hline Bolívar & $1 \%$ \\
\hline Tolima & $0,8 \%$ \\
\hline Nariño & $0,5 \%$ \\
\hline Huila & $0,5 \%$ \\
\hline Magdalena & $0,2 \%$ \\
\hline Cesar & $0,1 \%$ \\
\hline Guajira & $0,1 \%$ \\
\hline Otros & $8,2 \%$ \\
\hline
\end{tabular}

Fuente: (DANE, 2016). Elaboración Propia

\section{RESULTADOS:}

El sector automotor colombiano constituye el $4 \%$ del PIB, consolidándolo como uno de los sectores más importantes de la industria manufacturera nacional. El sector de autopartes ha tenido que afrontar en los últimos siete años una recesión mundial que ha ocasionado la baja en el precio del dólar, además de la crisis andina que generó una reducción en la oferta exportada a países estratégicos como Venezuela y Ecuador (Castro-Patiño, 2009). Sin embargo, el sector de autopartes ha buscado fortalecerse en mercados alternos de Centro y Suramérica, aprovechando la suscripción de los diversos tratados de libre comercio quedando a la expectativa de los retos que le impondrá el tratado de libre comercio con Corea del Sur, un país que es muy competitivo en el sector automotriz. (Rivera \& Padilla 2016).

\subsection{Dinámica Comercial Internacional Capitulo 87 en Colombia}

En la presente sección se presenta la dinámica comercial del capítulo 87 en Colombia, tomando como referencia las exportaciones, las importaciones, el destino de las exportaciones, el origen de las importaciones, los principales productos exportados y los principales productos importados del capítulo arancelario No 87.

\subsubsection{Exportaciones Capitulo 87 en Colombia}

En el gráfico No 2 se pueden detallar que las exportaciones de autopartes en el país se concentran principalmente en ciudades ubicadas a los principales puertos marítimos y aeropuertos. El departamento del Valle del cauca encabeza la exportación nacional de autopartes con una participación del $34 \%$ con montos equivalentes a USD $171.250,52$ seguido de Bogotá con el $25 \%$ por montos equivalentes correspondiente al $14,3 \%$ del total del sector en el país. Santander Ocupa el octavo lugar con una participación de 2,4\% sobre el total exportado por el sector autopartes de Colombia, correspondiente a USD $15.110,34$.

\section{Grafico No 2 Principales Departamentos Exportadores Capitulo 87}

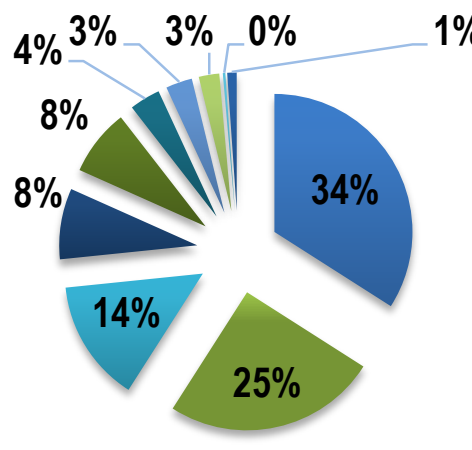
$1 \%$

Valle del Cauca
Bogotá D.C
Atlántico
- Cundinamarca
- Antioquia
- Caldas
Risaralda

Fuente: Programa de Transformación Productiva. Elaboración Propia

\subsubsection{Destino Exportaciones Capitulo 87 de Colombia}

Las exportaciones de autopartes de Colombia se dirigen principalmente a países vecinos, tal y como se observa en el cuadro No 14. Ecuador es el principal socio Comercial de Colombia respecto las autopartes, con ventas por USD 89.151,01 equivalentes a un $17,7 \%$ de las exportaciones del sector. Estados Unidos es el segundo país al cual se dirigió el $17 \%$ de las mercancías de sector, correspondiente a USD $85.625,26$. América Latina representó en el 2015 un mercado del $52,8 \%$, una cifra importante que indica tener buenas relaciones comerciales con estos países Es de destacar que los principales socios comerciales de las exportaciones del capítulo 87 de Colombia son Perú, México y Chile con quien Colombia hace parte de la Alianza del Pacifico. Las exportaciones de Colombia del capítulo 87 hacia los miembros de la Alianza del Pacifico representan el $28.7 \%$ de las exportaciones totales de Colombia de esta partida 
Julio Ramírez Montañez-Gustavo González Sarmiento-Marco Vásquez Méndez

arancelaria. Lo cual convierte a la Alianza del Pacifico en el escenario propicio para el desarrollo del sector autopartes de Colombia y la posibilidad de generar encadenamientos productivos con empresas del sector autopartes de esos países.

\section{Cuadro No 14 Destinos de Exportaciones de Autopartes de Colombia}

\begin{tabular}{|c|c|c|}
\hline $\begin{array}{c}\text { Principales } \\
\text { mercados de } \\
\text { exportación } \\
\text { Ene-Dic 2015 }\end{array}$ & (\% del total) & \multicolumn{2}{|c|}{ (\% del total) } \\
\hline Ecuador & $17,7 \%$ & $\begin{array}{c}\text { USD } \\
89.151,01\end{array}$ \\
\hline Estados Unidos & $17 \%$ & USD \\
\hline Venezuela & & $85.625,26$ \\
\hline Perú & $13,7 \%$ & USD \\
\hline & & $69.003,89$ \\
\hline México & $7,8 \%$ & USD \\
\hline & & $39.286,88$ \\
\hline Chile & $7,2 \%$ & USD \\
\hline & & $36.264,82$ \\
\hline & $6,4 \%$ & USD \\
\hline & & $32.235,39$ \\
\hline
\end{tabular}

Fuente: Trademap (2016)

\subsubsection{Principales Productos Exportados del Capítulo 87} por Colombia

Colombia exporta principalmente Acumuladores Eléctricos, Partes y accesorios de vehículos, y vidrios de seguridad, tal como se describe en el cuadro No 15.

\section{Cuadro No 15 Principales Productos Exportados por}

\section{Colombia del Capítulo 87}

\begin{tabular}{|c|c|}
\hline $\begin{array}{c}\text { Principales productos de exportación } \\
\text { Ene-Dic 2015 }\end{array}$ & (\% del total) \\
\hline Acumuladores eléctricos & $33,2 \%$ \\
\hline Partes y accesorios de vehículos & $18,1 \%$ \\
\hline
\end{tabular}

\begin{tabular}{|c|c|}
\hline Vidrio de seguridad & $10,2 \%$ \\
\hline $\begin{array}{c}\text { Carrocerías de vehículos automóviles, incluidas las } \\
\text { cabinas }\end{array}$ & \\
\hline Neumáticos nuevos de caucho & $7,8 \%$ \\
\hline & $7,3 \%$ \\
\hline
\end{tabular}

Fuente: Trademap (2016)

\subsubsection{Importaciones Capitulo 87 de Colombia}

Estados Unidos se posiciona como el principal país de origen de las importaciones del capítulo 87 hacia territorio Colombiano. De igual forma, el continente Asiático es el principal de origen de las importaciones de autopartes hacia Colombia, como lo es el caso de China con un $18 \%$, Japón con un $12.4 \%$ y Corea del Sur con $6.1 \%$.

\section{Cuadro No 16 Origen de importaciones de Autopartes}

\begin{tabular}{|c|c|}
\hline $\begin{array}{c}\text { Principales orígenes de importación } \\
\text { Ene-Dic 2015 }\end{array}$ & (\% del total) \\
\hline Estados Unidos & $20,6 \%$ \\
\hline China & $18 \%$ \\
\hline Japón & \\
\hline & $12,4 \%$ \\
\hline Zona Franca & $9,6 \%$ \\
\hline Brasil & \\
\hline Corea del Sur & \\
\hline & \\
\hline
\end{tabular}

Fuente: Trademap (2016) 


\subsubsection{Principales Productos de Importación del Capítulo 87}

Los neumáticos de caucho son el mayor producto importado del sector autopartes por parte de empresarios Colombianos con un $27.6 \%$ del total de importaciones del sector en el año 2015. Los partes y accesorios de vehículos son el segundo producto más demandado en Colombia por el sector autopartes con un $23.4 \%$ de las importaciones.

\section{Cuadro No 17 Autopartes Importadas en el 2015 por Colombia}

\begin{tabular}{|c|c|}
\hline $\begin{array}{c}\text { Principales productos de } \\
\text { importación } \\
\text { Ene-Dic 2015 }\end{array}$ & $\begin{array}{c}\text { (\% del } \\
\text { total) }\end{array}$ \\
\hline Neumáticos nuevos de caucho & $27,6 \%$ \\
\hline Partes y accesorios de vehículos & $23,4 \%$ \\
\hline $\begin{array}{c}\text { Centrifugadoras, aparatos para filtrar o } \\
\text { depurar líquidos o gases }\end{array}$ & $10,4 \%$ \\
\hline $\begin{array}{c}\text { Partes exclusiva o principalmente, para } \\
\text { motores }\end{array}$ & $8,3 \%$ \\
\hline $\begin{array}{c}\text { Acumuladores eléctricos, incluidos sus } \\
\text { separadores }\end{array}$ & $4,2 \%$ \\
\hline $\begin{array}{c}\text { Carrocerías de vehículos, incluidas las } \\
\text { cabinas }\end{array}$ & $3,4 \%$ \\
\hline
\end{tabular}

Fuente: Programa de Transformación Productiva (2015).

Elaboración Propia.

\subsection{Dinámica Comercial Internacional Capítulo 87 del Departamento de Santander}

En la sección final del presente artículo se presenta la dinámica comercial del capítulo 87 en el departamento de Santander, tomando como referencia las Exportaciones totales de Santander de autopartes comprendidas en las partidas $8706,8707,0708$ y 8714 , el destino de las exportaciones del Capítulo 87 desde el Departamento de Santander, las Empresas Exportadoras del Capítulo 87 del departamento de Santander, las Importaciones Capitulo 87 Departamento de Santander y las empresas importadoras de productos del capítulo 87 del departamento de Santander.

\subsubsection{Exportaciones Capitulo 87 Departamento de Santander}

Las exportaciones de autopartes del departamento de Santander han tenido una caída a partir del año 2012. La variación relativa del período es de $-68 \%$, es decir, la venta de estos artículos en el exterior han caído en más del $50 \%$. Para los productores regionales los Tratados de Libre Comercio TLC se han convertido en obstáculos que impiden una fácil actuación de ellos en el mercado local. Es más rentable para algunos empresarios convertirse en distribuidores de estas piezas y no productores. El punto crítico se muestra en la variación entre el año 2014-2015, donde tan solo en ese periodo de tiempo las exportaciones cayeron en $-57,31 \%$. En el cuadro No 16 se encuentra el comportamiento de las exportaciones de autopartes de Santander durante el período 2011-2015

\section{Cuadro No 18 Exportaciones totales de Santander de autopartes comprendidas en las partidas $8706,8707,0708$ y 8714}

\begin{tabular}{|c|c|c|c|c|}
\hline 2011 & $\mathbf{2 0 1 2}$ & $\mathbf{2 0 1 3}$ & $\mathbf{2 0 1 4}$ & $\mathbf{2 0 1 5}$ \\
& & & & \\
& & & & \\
\hline USD & USD & USD & USD & USD \\
14.351 .798$, & 15.418 .639$, & 12.489 .913$, & 10.753 .372$, & 4.589 .84 \\
57 & 33 & 06 & 73 & 0 \\
\hline
\end{tabular}

En el cuadro No 19 se muestra como el departamento de Santander se enfoca en la producción y exportación de partes de ejes con diferencial, que es uno de los productos más vendidos y con mayores índices representativos, seguido de las partes para vehículos contemplados en las partidas 8701-8705, haciendo referencia a automóviles de distintas características. La exportación de ejes con diferenciar también es significativa para la balanza comercial del departamento, esto se logra con la producción de la empresa Transejes, líder en la región en estos productos. 


\section{DINÁMICA DEL COMERCIO INTERNACIONAL DEL SECTOR AUTOPARTES DEL DEPARTAMENTO DE SANTANDER EN EL PERÍODO}

2011-2015

Julio Ramírez Montañez-Gustavo González Sarmiento-Marco Vásquez Méndez

\section{Cuadro No 19 Exportaciones de Santander por Subpartida Arancelaria.}

Fuente: SIEX-DIAN. Elaboración Propia

\begin{tabular}{|c|c|c|c|c|c|c|}
\hline $\begin{array}{c}\text { PARTI } \\
\text { DA }\end{array}$ & $\begin{array}{l}\text { DESCRI } \\
\text { PCIÓN }\end{array}$ & 2011 & 2012 & 2013 & 2014 & 2015 \\
\hline 87085 & Ejes con & USD & USD & USD & USD & USD \\
\hline 01100 & $\begin{array}{c}\text { diferenci } \\
\text { al }\end{array}$ & $\begin{array}{l}5.387 \\
788,32\end{array}$ & $\begin{array}{l}5.090 \\
847,54\end{array}$ & $\begin{array}{l}4.953 \\
112,21\end{array}$ & $\begin{array}{c}1.412 . \\
863,80\end{array}$ & $\begin{array}{c}5.737 \\
76\end{array}$ \\
\hline $\begin{array}{l}87085 \\
01900\end{array}$ & $\begin{array}{c}\text { partes } \\
\text { de ejes } \\
\text { con } \\
\text { diferenci } \\
\text { al, } \\
\text { incluso } \\
\text { provisto } \\
\text { s con } \\
\text { otros } \\
\text { órganos } \\
\text { de } \\
\text { transmis } \\
\text { ión }\end{array}$ & $\begin{array}{c}\text { USD } \\
209.76 \\
3,50\end{array}$ & $\begin{array}{c}\text { USD } \\
1.480 . \\
282,36\end{array}$ & $\begin{array}{c}\text { USD } \\
4.652 . \\
688,72\end{array}$ & $\begin{array}{c}\text { USD } \\
5.983 . \\
462,86\end{array}$ & $\begin{array}{c}\text { USD } \\
3.899 . \\
562,87\end{array}$ \\
\hline $\begin{array}{l}87089 \\
39100\end{array}$ & $\begin{array}{c}\text { platos } \\
\text { (prensa } \\
\text { s) y } \\
\text { discos }\end{array}$ & $\begin{array}{c}\text { USD } \\
9.127 \\
54\end{array}$ & $\begin{array}{c}\text { USD } \\
404,08\end{array}$ & $\begin{array}{c}\text { USD } \\
774,90\end{array}$ & -- & -- \\
\hline $\begin{array}{l}87089 \\
92100\end{array}$ & $\begin{array}{l}\text { transmis } \\
\text { iones } \\
\text { cardánic } \\
\text { as }\end{array}$ & $\begin{array}{c}\text { USD } \\
3.635 \\
348,62\end{array}$ & $\begin{array}{c}\text { USD } \\
4.699 . \\
326,75\end{array}$ & $\begin{array}{c}\text { USD } \\
2.132 . \\
993,67\end{array}$ & $\begin{array}{c}\text { USD } \\
526.74 \\
7,43\end{array}$ & $\begin{array}{c}\text { USD } \\
72.557\end{array}$ \\
\hline $\begin{array}{l}87089 \\
92900\end{array}$ & $\begin{array}{l}\text { partes } \\
\text { de } \\
\text { transmis } \\
\text { iones } \\
\text { cardánic } \\
\text { as }\end{array}$ & $\begin{array}{c}\text { USD } \\
45.360 \\
, 47\end{array}$ & $\begin{array}{c}\text { USD } \\
662.26 \\
1,41\end{array}$ & $\begin{array}{c}\text { USD } \\
555.72 \\
8,25\end{array}$ & $\begin{array}{c}\text { USD } \\
2.140 \\
624,66\end{array}$ & $\begin{array}{c}\text { USD } \\
510.06 \\
4,85\end{array}$ \\
\hline $\begin{array}{l}87089 \\
99900\end{array}$ & $\begin{array}{c}\text { las } \\
\text { demás } \\
\text { partes } \\
\text { para } \\
\text { vehículo } \\
\text { s } \\
\text { contemp } \\
\text { lados en } \\
\text { las } \\
\text { partidas } \\
8701- \\
8705\end{array}$ & $\begin{array}{c}\text { USD } \\
5.044 . \\
659,10\end{array}$ & $\begin{array}{c}\text { USD } \\
3.434 . \\
566,82\end{array}$ & $\begin{array}{c}\text { USD } \\
167.17 \\
2,00\end{array}$ & $\begin{array}{c}\text { USD } \\
544.64 \\
3,00\end{array}$ & -- \\
\hline
\end{tabular}

\subsubsection{Destino Exportaciones Capitulo 87 desde el Departamento de Santander}

Las exportaciones realizadas durante el 2015 señalan como la industria Santandereana de autopartes se ha enfocado casi en un $50 \%$ de sus exportaciones hacia el mercado de Ecuador con ventas por USD 2.225.613,42. El segundo destino es Venezuela con una participación del $24,73 \%$ con ventas por USD 529.667,54 y Chile con ventas por USD 1.135.067,43, correspondiente al $11,54 \%$ del total de las exportaciones del capítulo 87 del departamento de Santander.

En el cuadro No 20 se ilustra la participación de los mercados a los cuales Santander exportó autopartes comprendidas en las partidas 8706-8708 y 8714 .

\section{Cuadro No 20 Destinos Exportación Santander 2015}

\begin{tabular}{|c|c|c|}
\hline País & Exportaciones & $\begin{array}{c}\% \text { de } \\
\text { Participación }\end{array}$ \\
\hline Ecuador & USD 2.225.613,42 & $48.9 \%$ \\
\hline Venezuela & USD 529.667,54 & $24.73 \%$ \\
\hline Chile & USD 1.135.067,43 & $11.54 \%$ \\
\hline Perú & USD 227.197,08 & $4.95 \%$ \\
\hline Brasil & USD 176.708,84 & $3.85 \%$ \\
\hline Estados Unidos & USD 100.976,48 & $2.75 \%$ \\
\hline Bolivia & USD 50.488,24 & $2.2 \%$ \\
\hline Guatemala & USD 126.220,60 & $1.1 \%$ \\
\hline Fuente: SIEX-DIAN. Elaboración Propia & \\
\hline
\end{tabular}

\subsubsection{Empresas Exportadoras Capitulo 87 Departamento de Santander}

\section{La empresa TRANSEJES TRANSMISIONES} HOMOCINETICAS DE COLOMBIA S.A es la empresa exportadora más representativa del sector autopartes del departamento de Santander con ventas por US\$ 3.362.255, en el año 2015. La segunda empresa exportadora del Departamento de Santander es INDUSTRIA DE EJES Y TRANSMISIONES S.A con exportaciones por USD 1.075.496,10. En el cuadro № 10 se detalla las cantidad de operaciones realizadas durante el año por las empresas exportadoras, el valor en termino FOB, el destino de exportación de cada empresa, y el producto exportado. 


\section{Cuadro No 21 Empresas Exportadoras de Autopartes de Santander en el año 2015}

\begin{tabular}{|c|c|c|c|c|}
\hline EMPRESA & $\begin{array}{c}\text { Operacio } \\
\text { nes }\end{array}$ & VALOR FOB & $\begin{array}{l}\text { Principales } \\
\text { Destinos }\end{array}$ & $\begin{array}{c}\text { Principa } \\
\text { es } \\
\text { Product } \\
\text { os }\end{array}$ \\
\hline $\begin{array}{c}\text { Transejes } \\
\text { Transmisio } \\
\text { nes } \\
\text { Homocinéti } \\
\text { cas De } \\
\text { Colombia } \\
\text { S.A. }\end{array}$ & 70 & $\begin{array}{c}\text { USD } \\
3.362 .255,76\end{array}$ & $\begin{array}{c}\text { Ecuador } \\
72,86 \% ; \\
\text { Venezuela } \\
\text { 17,14\%; } \\
\text { Brasil 10\% }\end{array}$ & $\begin{array}{c}8708501 \\
900\end{array}$ \\
\hline $\begin{array}{c}\text { Industria } \\
\text { De Ejes Y } \\
\text { Transmisio } \\
\text { nes S.A. }\end{array}$ & 79 & $\begin{array}{c}\text { USD } \\
1.075 .496,10\end{array}$ & $\begin{array}{c}\text { Ecuador } \\
\text { 48,10\%; } \\
\text { Chile } \\
\text { 26,58\%; } \\
\text { Perú } \\
11,39 \%\end{array}$ & $\begin{array}{c}87085 \\
01900 \\
87089 \\
92100 \\
87089 \\
92900\end{array}$ \\
\hline $\begin{array}{l}\text { Sol Parts } \\
\text { Distribuidor } \\
\text { a Limitada }\end{array}$ & 23 & $\begin{array}{c}\text { USD } \\
59.581,81\end{array}$ & $\begin{array}{c}\text { Venezuela } \\
100 \%\end{array}$ & $\begin{array}{c}87141 \\
01000 \\
87141 \\
09000 \\
87149 \\
30000\end{array}$ \\
\hline $\begin{array}{l}\text { Importador } \\
\text { a De } \\
\text { Repuestos } \\
\text { De } \\
\text { Colombia } \\
\text { S.A.S. } \\
\text { Imrepcol }\end{array}$ & 3 & $\begin{array}{c}\text { USD } \\
55.151,78\end{array}$ & EEUU $100 \%$ & $\begin{array}{c}87085 \\
01900 \\
87089 \\
93900\end{array}$ \\
\hline $\begin{array}{l}\text { Solutra De } \\
\text { Colombia } \\
\text { Ltda. }\end{array}$ & 3 & $\begin{array}{c}\text { USD } \\
32.121,30\end{array}$ & $\begin{array}{c}\text { Venezuela } \\
100 \%\end{array}$ & $\begin{array}{c}8708809 \\
090\end{array}$ \\
\hline $\begin{array}{l}\text { Madasa } \\
\text { S.A.S. }\end{array}$ & 2 & USD 4.836,96 & $\begin{array}{c}\text { Guatemala } \\
100 \%\end{array}$ & $\begin{array}{c}8714101 \\
000\end{array}$ \\
\hline $\begin{array}{l}\text { Trienergy } \\
\text { S.A. }\end{array}$ & 1 & USD 346,13 & EEUU $100 \%$ & $\begin{array}{l}87088 \\
02010\end{array}$ \\
\hline $\begin{array}{l}\text { C.I. Del } \\
\text { Tropiko } \\
\text { Limitada }\end{array}$ & 1 & USD 50,00 & $\begin{array}{c}\text { Venezuela } \\
100 \%\end{array}$ & $\begin{array}{c}8708992 \\
100\end{array}$ \\
\hline
\end{tabular}

Fuente: SIEX-DIAN. Elaboración Propia

4.2.4 Importaciones Capitulo 87 Departamento de Santander

Las importaciones de autopartes en el Departamento han tenido fluctuaciones dentro del período evaluado. La variación relativa del período cerró en $-26,4 \%$ y se notan dos picos. El primero en el 2012 con USD 39,7 millones y el segundo en el 2014 con USD 36,1 millones. En el cuadro No 19 se presenta el comportamiento de las importaciones de autopartes en Santander entre el periodo 2011-2015 de las partidas $8706-8708$ y 8714 .

\section{Cuadro No 22 Importaciones de Autopartes en Santander}

\begin{tabular}{|c|c|c|c|c|}
\hline $\mathbf{2 0 1 1}$ & $\mathbf{2 0 1 2}$ & $\mathbf{2 0 1 3}$ & $\mathbf{2 0 1 4}$ & $\mathbf{2 0 1 5}$ \\
\hline USD & USD & USD & USD & USD \\
36.748 .929 & & & 36.133. & \\
& 39.788. & 31.015. & 596 & 27.044 .06 \\
& 205 & 733 & & 2,88 \\
\hline
\end{tabular}

Las importaciones del sector autopartes del departamento de Santander provinieron principalmente durante el año 2015 de Estados Unidos con un 28\% de las importaciones, seguido de China con un 20\% de las importaciones y Brasil con un $12 \%$ de las importaciones del sector autopartes del departamento de Santander. De igual forma es de destacar que a pesar de que México es un gran productor mundial de autopartes, el empresariado santandereano prefirió en el 2015 importar principalmente desde Asia y Estados Unidos. El mercado asiático vendió al departamento alrededor del $33 \%$ del de las autopartes importadas provenientes de China, Taiwán y Corea del Sur. Este último país fue referente de amenaza para la producción regional, debido a que sus bajos precios podrían poner en jaque a los empresarios de autopartes de Santander. En el gráfico No 4 se ilustra la participación de los proveedores de autopartes de Santander durante el 2015.

\section{Cuadro No 23 Origen de las importaciones Santandereanas de Autopartes}

\begin{tabular}{|c|c|c|}
\hline $\begin{array}{c}\text { Origen Importación } \\
\text { Santander 2015 }\end{array}$ & Monto & \% de Participación \\
\hline Estados Unidos & USD 7.572.337,36 & $28 \%$ \\
\hline China & USD 5.408.812,40 & $20 \%$ \\
\hline Brasil & USD 3.245.287,44 & $12 \%$ \\
\hline Taiwán & USD 2.704.406,20 & $10 \%$ \\
\hline Reino Unido & USD 1.352.203,10 & $5 \%$ \\
\hline Corea del sur & USD 811.321,86 & $3 \%$ \\
\hline Otros & USD 5.949.693,64 & $22 \%$ \\
\hline
\end{tabular}

Fuente: SIEX-DIAN. Elaboración Propia

4.2.5 Principales Empresas Importadoras Capítulo 87 del Departamento de Santander 
Julio Ramírez Montañez-Gustavo González Sarmiento-Marco Vásquez Méndez

El cuadro No 24 presenta el listado de las diez mayores empresas importadoras de autopartes de Santander durante el año 2015. Los productos más importados son partes para bicicleta y motocicleta, y accesorios y partes de vehículos.

\section{Cuadro N 24 Top 10 Importadoras De Autopartes En} Santander 2015

\begin{tabular}{|c|c|c|c|c|}
\hline Empresa & $\begin{array}{l}\text { Operacio } \\
\text { nes }\end{array}$ & Valor CIF & $\begin{array}{c}\text { Origen } \\
\text { (Principale } \\
\text { s) }\end{array}$ & $\begin{array}{l}\text { Principale } \\
\text { s } \\
\text { Importaci } \\
\text { ones }\end{array}$ \\
\hline \multirow{3}{*}{$\begin{array}{l}\text { Len } \\
\text { Importacion } \\
\text { es Limitada }\end{array}$} & \multirow[t]{3}{*}{520} & \multirow{3}{*}{$\begin{array}{c}\text { USD } \\
11.843 .295,7 \\
4\end{array}$} & \multirow{3}{*}{$\begin{array}{c}\text { China 63\%; } \\
\text { Taiwán } \\
\text { 14,67\%; } \\
\text { Italia } \\
12,15 \%\end{array}$} & $\begin{array}{c}87149100 \\
00\end{array}$ \\
\hline & & & & $\begin{array}{c}87149400 \\
00\end{array}$ \\
\hline & & & & $\begin{array}{c}87149900 \\
00\end{array}$ \\
\hline \multirow{3}{*}{$\begin{array}{l}\text { Industria De } \\
\text { Ejes Y } \\
\text { Transmision } \\
\text { es S.A. }\end{array}$} & \multirow[t]{3}{*}{326} & \multirow[t]{3}{*}{$\begin{array}{c}\text { USD } \\
5.659 .475,98\end{array}$} & \multirow{3}{*}{$\begin{array}{c}\text { EEUU } \\
\text { 46,52\%; } \\
\text { Ecuador26, } \\
54 \% \text {; China } \\
9,47 \%\end{array}$} & $\begin{array}{c}87085019 \\
00\end{array}$ \\
\hline & & & & $\begin{array}{c}87089921 \\
00\end{array}$ \\
\hline & & & & $\begin{array}{c}87089929 \\
00\end{array}$ \\
\hline \multirow{3}{*}{$\begin{array}{c}\text { Transejes } \\
\text { Transmision } \\
\text { es } \\
\text { Homocinétic } \\
\text { as De } \\
\text { Colombia } \\
\text { S.A. }\end{array}$} & \multirow[t]{3}{*}{259} & \multirow{3}{*}{$\begin{array}{c}\text { USD } \\
2.526 .326,20\end{array}$} & \multirow{3}{*}{$\begin{array}{c}\text { Brasil } \\
64,17 \% ; \\
\text { EEUU } \\
22,40 \% \text {; } \\
\text { Taiwán } \\
6,86 \%\end{array}$} & 87085019 \\
\hline & & & & \\
\hline & & & & $\begin{array}{c}87089999 \\
00\end{array}$ \\
\hline \multirow{3}{*}{$\begin{array}{l}\text { Industrias } \\
\text { Bicicletas } \\
\text { Milán S.A. }\end{array}$} & \multirow[t]{3}{*}{133} & \multirow[t]{3}{*}{$\begin{array}{c}\text { USD } \\
1.705 .758,81\end{array}$} & \multirow{3}{*}{$\begin{array}{c}\text { China } \\
56,84 \% ; \\
\text { Panamá } \\
\text { 26,98\%; } \\
\text { Taiwán } \\
\text { 15,34\% }\end{array}$} & $\begin{array}{c}87149100 \\
00\end{array}$ \\
\hline & & & & $\begin{array}{c}87149210 \\
00\end{array}$ \\
\hline & & & & $\begin{array}{c}87149900 \\
00\end{array}$ \\
\hline \multirow[t]{3}{*}{ DCN S.A.S. } & \multirow[t]{3}{*}{138} & \multirow[t]{3}{*}{$\begin{array}{c}\text { USD } \\
1.686 .977,94\end{array}$} & \multirow{3}{*}{$\begin{array}{c}\text { Brasil } \\
48,53 \% ; \\
\text { EEUU } \\
35,19 \% ; \\
\text { China } \\
4,61 \%\end{array}$} & $\begin{array}{c}87083010 \\
00\end{array}$ \\
\hline & & & & $\begin{array}{c}87083025 \\
00\end{array}$ \\
\hline & & & & $\begin{array}{c}87089999 \\
00\end{array}$ \\
\hline \multirow{3}{*}{$\begin{array}{c}\text { Autopartes } \\
\text { Castelmotor } \\
\text { s S.A.S }\end{array}$} & \multirow[t]{3}{*}{201} & \multirow[t]{3}{*}{$\begin{array}{c}\text { USD } \\
1.097 .407,92\end{array}$} & \multirow{3}{*}{$\begin{array}{c}\text { EEUU } \\
92,56 \% ; \\
\text { Corea del } \\
\text { Sur 5,16\%; } \\
\text { Francia } \\
1,06 \%\end{array}$} & $\begin{array}{c}87085029 \\
00\end{array}$ \\
\hline & & & & $\begin{array}{c}87088090 \\
90\end{array}$ \\
\hline & & & & $\begin{array}{c}87089400 \\
10\end{array}$ \\
\hline \multirow{3}{*}{$\begin{array}{c}\text { Safrenos } \\
\text { Rangel } \\
\text { S.A.S }\end{array}$} & \multirow[t]{3}{*}{146} & \multirow[t]{3}{*}{$\begin{array}{c}\text { USD } \\
854.064,19\end{array}$} & \multirow{3}{*}{$\begin{array}{c}\text { EEUU } \\
69,29 \% \\
17,15 \% ; \\
\text { Italia } 7,84 \%\end{array}$} & $\begin{array}{c}87083022 \\
90\end{array}$ \\
\hline & & & & $\begin{array}{c}87088010 \\
90\end{array}$ \\
\hline & & & & $\begin{array}{c}87089929 \\
00\end{array}$ \\
\hline $\begin{array}{l}\text { Redemotos } \\
\text { S.A.S. }\end{array}$ & 3 & $\begin{array}{c}\text { USD } \\
276.862,91\end{array}$ & $\begin{array}{l}\text { China } \\
100 \%\end{array}$ & $\begin{array}{c}87141090 \\
00\end{array}$ \\
\hline $\begin{array}{l}\text { Comercializ } \\
\text { adora } \\
\text { Mundo } \\
\text { Importado } \\
\text { S.A.S }\end{array}$ & 6 & $\begin{array}{c}\text { USD } \\
228.602,22\end{array}$ & $\begin{array}{c}\text { China } \\
92,42 \% \\
\text { EAU } 7,58 \%\end{array}$ & $\begin{array}{c}87087010 \\
00\end{array}$ \\
\hline
\end{tabular}

\begin{tabular}{|c|c|c|c|c|}
\hline Repuestos & 29 & USD & Japón & 87088010 \\
Autofrenos & & $225.929,97$ & $66,30 \% ;$ & 10 \\
\hline Limitada & & & EEUU & 87089933 \\
& & & $15,25 \% ;$ & 00 \\
& & & Taiwán & 87089939 \\
& & & $12,77 \%$ & 00 \\
\hline
\end{tabular}

Fuente: SIEX-DIAN. Elaboración Propia

\section{CONCLUSION:}

Bogotá es el mayor centro de producción del sector autopartes de Colombia y Cundinamarca es el departamento que mayor número de plazas de trabajo creó en el año 2015. Las empresas de autopartes del sector están concentradas principalmente en Bogotá con 139 establecimientos, el segundo departamento con más empresas del sector autopartes es Antioquia con 48 empresas seguido por el departamento de Cundinamarca con 33, lo cual indica que la región Andina del país tiene 172 establecimientos productores de autopartes.

El departamento líder en generación de empleo en la cadena del sector autopartes es el Departamento de Cundinamarca aportando el $49 \%$ del empleo nacional tomando como referencia a Bogotá con un $40 \%$ y los municipios vecinos del departamento de Cundinamarca con un 9\%. El segundo departamento generador de empleo de la cadena autopartes en el Valle del Cauca con un $16 \%$ de la cadena del sector autopartes seguido por Risaralda con un $10 \%$ de participación del empleo a nivel nacional. Por su parte, la distribución de la producción del sector autopartes de Colombia está liderada por Bogotá con un $45 \%$ de la Producción total de este sector. El segundo departamento de mayor producción de la cadena de autopartes es Antioquía con el $31 \%$ de la producción, seguido por el departamento del Valle del Cauca con el 7\% La producción del sector autopartes del departamento de Santander se reduce a tan solo el $2 \%$ de la producción de autopartes del país.

La oferta exportable de Colombia del sector autopartes se limita a productos del capítulo No 87 donde se destaca la exportación de acumuladores eléctricos, partes y accesorios de vehículos, y vidrios de seguridad. Por su parte los neumáticos de caucho son el mayor producto importado del sector autopartes por parte de empresarios Colombianos con un $27.6 \%$ del total de importaciones del sector en el año 2015. Los partes y accesorios de vehículos son el segundo producto más demandado en Colombia por el sector autopartes con un $23.4 \%$ de las importaciones. El departamento del Valle del Cauca es el líder en las exportaciones del sector autopartes a nivel nacional con una participación del $34 \%$, seguido de Bogotá con el $25 \%$, donde la mayoría de las exportaciones se dirigen hacia sus Zonas Francas, y en tercer lugar Atlántico con un 14,3\%. Santander Ocupa el octavo lugar con una 
participación de 2,4\% sobre el total exportado por el sector autopartes de Colombia. Es de destacar que los principales socios comerciales de las exportaciones del capítulo 87 de Colombia son Perú, México y Chile con quien Colombia hace parte de la Alianza del Pacifico. Las exportaciones de Colombia del capítulo 87 hacia los miembros de la Alianza del Pacifico representan el $28.7 \%$ de las exportaciones totales de Colombia de esta partida arancelaria. Lo cual convierte a la Alianza del Pacifico en el escenario propicio para el desarrollo del sector autopartes de Colombia y la posibilidad de generar encadenamientos productivos con empresas del sector autopartes de esos países.

En cuanto al departamento de Santander el patrón de producción, la cadena autopartes está enfocada en la producción y exportación de partes de ejes con diferencial, platos, prensas y discos y transmisiones cardánicas. En el año 2015, la cadena del sector autopartes del departamento de Santander aportó a la producción de este sector un $2 \%$ de la producción total del país, participó con el $3,23 \%$ de la generación de empleo en este sector en el ámbito nacional. Las exportaciones de autopartes del departamento de Santander han tenido una caída a partir del año 2012, teniendo una variación negativa en el período 2011-2015 de (-68\%). Las exportaciones realizadas durante el 2015 señalan que el principal mercado de exportación es Ecuador con un $50 \%$ de sus exportaciones. La empresa TRANSEJES TRANSMISIONES HOMOCINETICAS DE COLOMBIA S.A es la empresa exportadora más representativa del sector autopartes del departamento de Santander con ventas por US\$ 3.362.255. Por su parte, las importaciones del sector autopartes del departamento de Santander provinieron principalmente durante el año 2015 de Estados Unidos con un $28 \%$ de las importaciones, seguido de China con un $20 \%$ de las importaciones y Brasil con un $12 \%$ de las importaciones del sector autopartes del departamento de Santander. Len Importaciones Limitada e Industria de Ejes y Transmisiones S.A. son las dos principales empresas importadoras del sector autopartes del Departamento de Santander.

\section{REFERENCIAS:}

Acevedo López, M. P., Rodríguez Duarte, M., \& Santana Martínez, G. P. (2014). Oportunidades del sector autopartes del departamento de Santander en el TLC con Chile.

Castro, L. Industria automotriz, adelante a pesar de la crisis mundial. 2009. Metal Actual.
Cámara de Comercio de Bucaramanga (2015). Compite 360. Observatorio de Competitividad

Cortes, J. A. Z., Benítez, A. F. Á., \& Moreno, S. R. (2015). Caracterización del sector autopartes-automotor en Colombia. Escenarios: empresa y territorio, 2(2), 227-240. Departamento Nacional de Estadística. (DANE). 2016.

SIEX-DIAN. Dirección de Impuestos y Aduanas Nacionales. Sistema Integrado de Estadística de Comercio Exterior. 2016

Escandón-Barbosa, D. M., \& Hurtado-Ayala, A. (2013). Internacionalización de empresas bajo la perspectiva de recursos y capacidades: caso sector autopartes. International Business, 32, 327-346.

Hormaza, E., Baquero, A., Piza, P., \& Tovar, S. (2012). Turbulencia empresarial en Colombia: el caso de sector de autopartes.

Trade Map (2016) Estadísticas del Comercio para el Desarrollo Internacional de las empresas Datos Comerciales Mensuales, Trimestrales y Anuales.

Programa de Transformación Productiva, Cadenas Priorizadas. Ministerio de Comercio, Industria y Turismo de Colombia. 2015

Metalmecánica. (Febrero de 2015). Internacional metalmecánica.

Reina, M., \& Oviedo, S. (2014). Importancia económica del sector automotor en Colombia.

Rivera-Godoy, Jorge Alberto; Padilla-Ospina, Ana Milena; (2016). Sector autopartes en Colombia: comportamiento financiero durante el período 2008-2014. Entramado, Enero-Junio, 12-29.

Silva, J. P. P. (2013). Caracterización del sector automotor y condiciones de internacionalización en Bogotá. Gestión \& Sociedad, 6(1), 81-89. 